\title{
Identification of genes associated with tongue cancer in patients with a history of tobacco and/or alcohol use
}

\author{
YIN ZHAO $^{1}$, DONGNA FU ${ }^{2}$, CHENGBI XU ${ }^{1}$, JINGPU YANG $^{1}$ and ZONGGUI WANG ${ }^{1}$ \\ ${ }^{1}$ Department of Otolaryngology, Head and Neck Surgery, The Second Hospital of Jilin University; \\ ${ }^{2}$ Department of Otolaryngology, Changchun People's Hospital, Changchun, Jilin 130041, P.R. China
}

Received July 8, 2015; Accepted October 14, 2016

DOI: 10.3892/ol.2016.5497

\begin{abstract}
The present study aimed to identify genes associated with tongue cancer in patients with a history of tobacco and/or alcohol use. Microarray dataset GSE42023, including 10 tissue samples of tongue cancer from patients with a history of tobacco and/or alcohol use (habit group) and 11 tissue samples of non-habit-associated tongue cancer (non-habit group), were downloaded from the Gene Expression Omnibus database. Differentially-expressed genes (DEGs) between the habit and non-habit groups were identified using the Linear Models for Microarray Data software package. The enrichment functions and pathways of these genes were subsequently predicted using Gene Ontology and Kyoto Encyclopedia of Genes and Genomes analysis. Transcription factors (TFs) and tumor-associated genes (TAGs) were selected from the DEGs using the Encyclopedia of DNA Elements database and the TAG database, respectively. Protein-protein interaction (PPI) networks for DEGs were constructed using Cytoscape. In addition, functional module analysis was performed using BioNet. This analysis identified 642 DEGs between the habit and non-habit groups, including 200 upregulated and 442 downregulated genes. The majority of upregulated DEGs were functionally enriched in the regulation of apoptosis and the calcium signaling pathway. The majority of downregulated DEGs were functionally enriched in fat cell differentiation and the adipocytokine signaling pathway. In addition, $31 \mathrm{TFs}$ and 42 TAGs were identified from the DEGs. Furthermore, this analysis demonstrated that certain DEGs, including AKT serine/threonine kinase 1 (AKT1), E1A binding protein p300 (EP300), erb-b2 receptor tyrosine kinase 2 (ERBB2) and epiregulin (EREG), had high connectivity degrees in the PPI networks and/or functional
\end{abstract}

Correspondence to: Dr Zonggui Wang, Department of Otolaryngology, Head and Neck Surgery, The Second Hospital of Jilin University, 218 Ziqiang Street, Changchun, Jilin 130041, P.R. China

E-mail: wangmidg@163.com

Key words: tongue cancer, differentially-expressed genes, protein-protein interaction, functional module modules. Overall, DEGs in a functional module, such as $A K T 1, E P 300, E R B B 2$ and $E R E G$, may serve important roles in the development of tongue cancer in patients with a history of tobacco and/or alcohol use. These DEGs are potential therapeutic targets for the treatment of tongue cancer in these groups.

\section{Introduction}

Oral cancer is the most frequently observed cancer of the head and neck region worldwide, with $\sim 363,000$ new cases reported annually and a mortality rate of $\sim 50 \%(1,2)$. The tongue is a vital organ that serves an essential role in speech and swallowing. Tongue cancer, a form of oral cancer, has become one of the greatest challenges in the head and neck cancer field (3). It has been reported that tongue cancer comprises between 22 and $49 \%$ of all oral cancer (4). Tongue cancer begins as a small lump and may spread throughout the tongue and to the gums (5). It has been estimated that $6-7 \%$ of tongue cancer occurs in patients $<40$ years old (6).

Tongue cancer may be caused by numerous factors, including old age, geographical location, family history, nutritional deficiencies, infectious agents, and chronic alcohol and tobacco use (7), however, the exact cause is unknown. A previous study demonstrated that cyclin D1 was overexpressed in patients with anterior tongue cancer with no history of tobacco and alcohol use, and postulated that it may contribute to the development of this cancer. A total of 18 DEGs were identified in this study (8). Another study reported that tumor protein p53, BCL2 associated X apoptosis regulator and BCL2 apoptosis regulator were associated with squamous cell cancer of the tongue (9). Therefore, although previous studies have identified a number of genes and proteins associated with tongue cancer, the exact pathogenesis of the disease remains unknown.

The present study investigated gene expression profiles to identify differentially-expressed genes (DEGs) between tongue cancer from patients with a history of tobacco and/or alcohol use (habit group) and tongue cancer from non-habit-associated patients (non-habit group). Gene Ontology (GO) and Kyoto Encyclopedia of Genes and Genomes (KEGG) pathway enrichment analysis were then performed to analyze the DEGs. Several key genes associated with habit-associated tongue cancer were identified 
Table I. Details of patients with habit and non-habit associated tongue cancer in the GSE42023 microarray dataset.

\begin{tabular}{|c|c|c|c|c|}
\hline Category & Sample number & Gender $(\mathrm{M} / \mathrm{F})$ & Age (years) & Tumor grade \\
\hline \multirow{10}{*}{$\begin{array}{l}\text { Habit-associated } \\
\text { tongue cancer samples }\end{array}$} & & $M$ & 27 & Moderately-differentiated \\
\hline & 1 & $\mathbf{M}$ & $\begin{array}{l}31 \\
45\end{array}$ & $\begin{array}{l}\text { Moderately-dimerentiated } \\
\text { Moderately-differentiated }\end{array}$ \\
\hline & 3 & $M$ & 52 & Moderately-differentiated \\
\hline & 4 & $M$ & 42 & Moderately-differentiated \\
\hline & 5 & $M$ & 45 & Well-differentiated \\
\hline & 6 & $\mathrm{M}$ & 42 & Well-differentiated \\
\hline & 7 & M & 41 & Well-differentiated \\
\hline & 8 & M & 52 & Well-differentiated \\
\hline & 9 & M & 67 & Well-differentiated \\
\hline & 10 & $\mathrm{~F}$ & 48 & Moderately-differentiated \\
\hline \multirow[t]{12}{*}{$\begin{array}{l}\text { Non-habit-associated } \\
\text { tongue cancer samples }\end{array}$} & 1 & M & 30 & Moderately-differentiated \\
\hline & 2 & M & 36 & Moderately-differentiated \\
\hline & 3 & M & 37 & Well-differentiated \\
\hline & 4 & $\mathrm{~F}$ & 50 & Well-differentiated \\
\hline & 5 & $\mathrm{~F}$ & 80 & Well-differentiated \\
\hline & 6 & $\mathrm{~F}$ & 40 & Moderately-differentiated \\
\hline & 7 & $\mathrm{~F}$ & 25 & Well-differentiated \\
\hline & 8 & $\mathrm{~F}$ & 46 & Moderately-differentiated \\
\hline & 9 & $\mathrm{~F}$ & 50 & Moderately-differentiated \\
\hline & 10 & $\mathrm{~F}$ & 63 & Well-differentiated \\
\hline & 11 & $\mathrm{~F}$ & 70 & Well-differentiated \\
\hline & 12 & $\mathrm{~F}$ & 56 & Well-differentiated \\
\hline
\end{tabular}

Microarray dataset GSE42023 was obtained from the Gene Expression Omnibus database and was originally produced by Sebastian et al (8). M, male; F, female.

through protein-protein interaction (PPI) network and functional module analysis. These results provide insight into the molecular mechanisms underlying habit-associated tongue cancer. In addition, the key DEGs identified are potential therapeutic targets for the treatment of tongue cancer in patients with a history of tobacco and/or alcohol use.

\section{Materials and methods}

Microarray data. The gene expression profile of microarray dataset GSE42023 was obtained from the Gene Expression Omnibus (GEO) database (www.ncbi.nlm.nih.gov/geo). This dataset was originally produced using the HumanHT-8 v3.0 Gene Expression BeadChip Array (Illumina, Inc., San Diego, CA, USA) (8). Gene expression data from 22 human anterior tongue cancer tissue samples were analyzed in this study, including 10 habit-associated samples, which were obtained from patients who had a long history (>10 years) of tobacco and/or alcohol use, in addition to 12 non-habit associated samples, which were taken from patients who had no prior history of tobacco and/or alcohol use. Details of the patients included in this dataset are listed in Table I. The gene expression data of all samples was pre-processed through background correction, quantile normalization, probe summarization and probe ID to gene symbol using the
Robust Multi-array Average algorithm (10) in the affy software package (version 1.8.31) of Bioconductor (http://www. bioconductor.org/packages/release/bioc/html).

$D E G$ analysis. The Linear Models for Microarray Data software package (version 3.16.8) (11) from Bioconductor (version 2.12; http://www.bioconductor. org/packages/release/bioc/html/limma.html) was used to identify DEGs between the habit and non-habit groups. DEGs with a cutoff criteria of $\mathrm{P}<0.05$ and $\log _{2}$ fold-changel value $\geq 1$ were used for screening.

GO and KEGG pathway enrichment analysis. The Database for Annotation, Visualization and Integrated Discovery (DAVID; version 6.7; https://david.ncifcrf.gov) (12) was used to identify the GO (13) biological process associated with the DEGs identified. KEGG (14) pathway enrichment analysis was subsequently used to identify the primary signaling pathways the DEGs functioned in. $\mathrm{P}<0.05$ calculated by Fisher's exact test was used as the cutoff criterion for statistically significant GO and KEGG enrichment analysis.

Screening for transcription factors (TFs) and tumor-associated genes (TAGs). TFs and TAGs were identified from the DEGs using the Encyclopedia of DNA Elements database (https://www. 


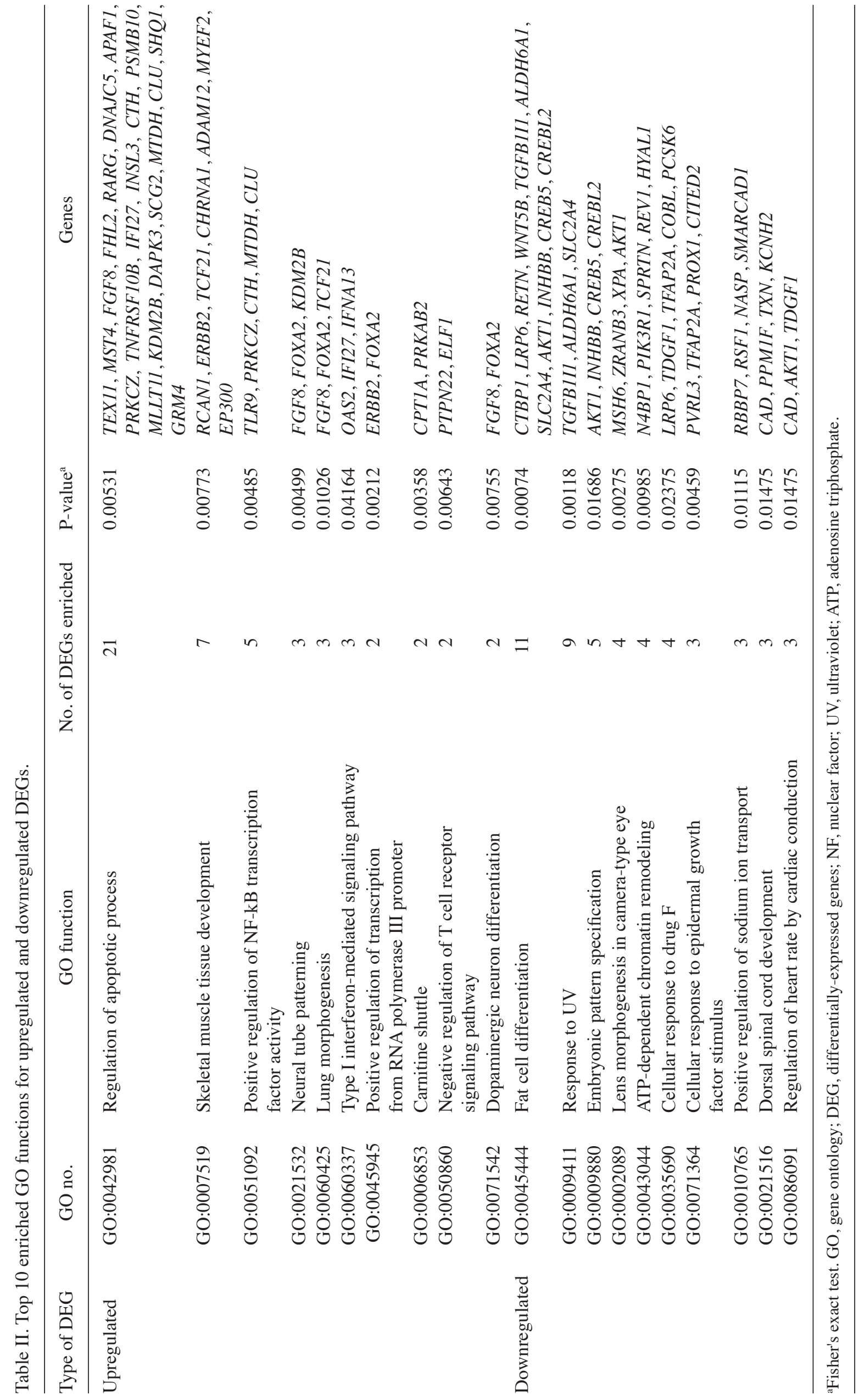




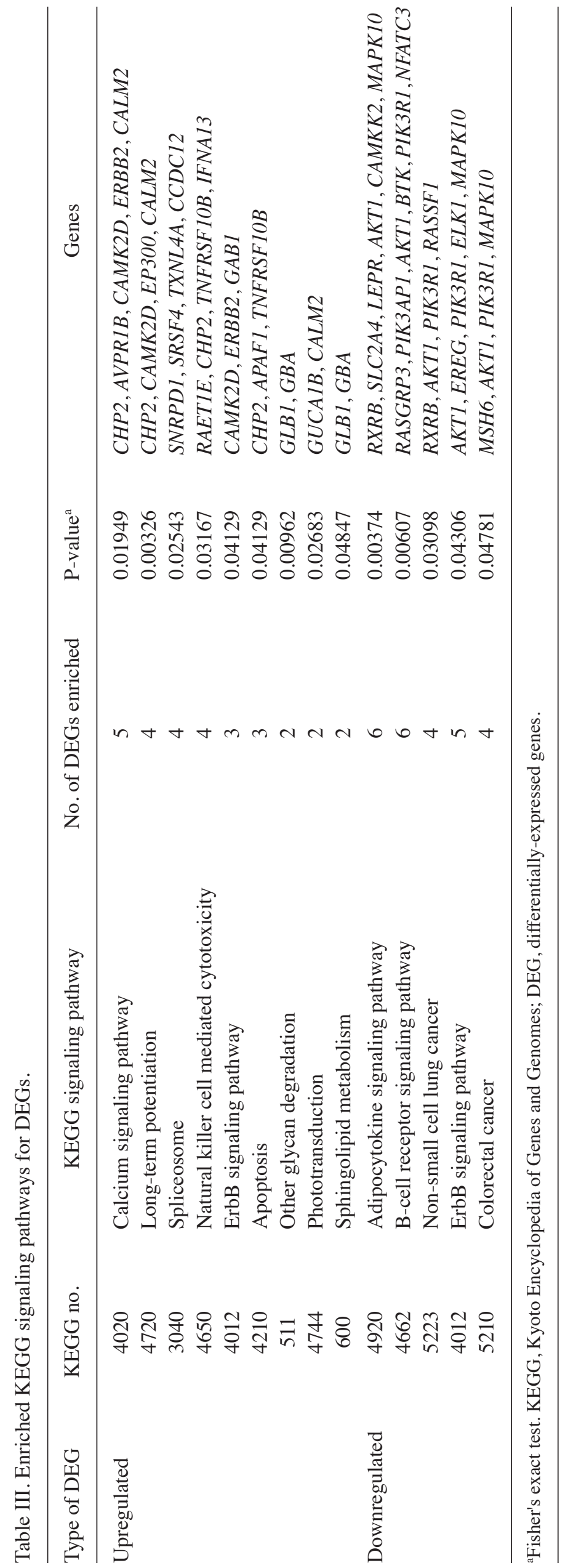


Table IV. TFs and TAGs among the DEGs.

\begin{tabular}{|c|c|c|c|c|}
\hline \multirow[b]{2}{*}{ Type of DEG } & \multicolumn{2}{|r|}{ TFs } & \multicolumn{2}{|r|}{ TAGs } \\
\hline & $\begin{array}{l}\text { No. of } \\
\text { genes }\end{array}$ & Genes & $\begin{array}{l}\text { No. of } \\
\text { genes }\end{array}$ & Genes \\
\hline Upregulated & 10 & $\begin{array}{l}\text { EP300, RARG, HOXB 13, } \\
\text { RORA, FOXA2, TCF } 21, \text { ELF, SIX5, } \\
\text { CCNT2, SUPT4H1 }\end{array}$ & 13 & $\begin{array}{l}\text { ERBB2, FGF8, MLLT11, MT1G, APAF1, } \\
\text { HOXB13, TNFRSF1OB, PDLIM4, } \\
\text { FOXA2, DAPK3, CLU, MTUS1, FHL2 }\end{array}$ \\
\hline Downregulated & 21 & $\begin{array}{l}\text { CTBP1, GTF } 2 A 1, \text { RORB, RXRB, } \\
\text { HOXB4, TGFB1I1, LMX1B, NR2F6, } \\
\text { KCNIP3, CDX4, SKIL, GABPB2, } \\
\text { MEIS3, NKX6-1, PAX3, ELK1, } \\
\text { NFATC3, SIM1, FOXD1, PROX1, } \\
\text { RFX5 }\end{array}$ & 28 & $\begin{array}{l}\text { MLF1, FGF20, CTTN, SKIL, AKT1, } \\
\text { EWSR1, ELK1, DCUN1D1, CTBP1, } \\
\text { PTPN2, RBBP7, FBXO32, TGFBI, } \\
\text { SIRT3, NEO1, RARRES1, PER1, } \\
\text { SPINK7, CBFA2T3, ENC1, CREBL2, } \\
\text { PROX1, RASSF1, MSH6, PAX3, DDX6, } \\
\text { TFAP2A, DHX16 }\end{array}$ \\
\hline
\end{tabular}

TF, transcription factor; TAG, tumor-associated gene; DEG, differentially-expressed genes.

encodeproject.org) (15) and the TAG database (http://www. binfo.ncku.edu.tw/TAG) (16), respectively.

PPI network construction. The Search Tool for the Retrieval of Interacting Genes (STRING; version 9.05; http://string-db.org) database, which provides experimental and predicted PPI information (17), was used to analyze the PPI network for the DEGs. A confidence score $>0.4$ was chosen as the threshold for a significant interaction. Finally, the PPI network for the remaining DEGs was visualized using Cytoscape software (version 3.0.0; www.cytoscape.org) (18).

Screening and analysis of the functional module. The BioNet Package (version 1.8.0; http://bionet.bioapps.biozentrum. uni-wuerzburg.de) provides a set of statistics for the analysis of gene expression data and biological networks (19). The functional module for DEGs was obtained based on BioNet analysis of the PPI network. A false discovery rate $<0.005$ was used as the cutoff criterion for functional module screening. GO and KEGG enrichment analysis of functional modules was performed using DAVID, with a statistically significant cutoff criterion of $\mathrm{P}<0.05$.

\section{Results}

Identification of DEGs. The microarray dataset GSE42023 was obtained from the GEO database in order to identify the DEGs between the habit and non-habits groups. In total, 642 DEGs were identified in the habit group compared with the non-habit group, including 200 upregulated and 442 downregulated DEGs.

GO and KEGG functional enrichment analysis. GO enrichment analysis demonstrated that the upregulated DEGs were enriched in 29 biological processes, including regulation of apoptosis $(\mathrm{P}=0.00531)$, skeletal muscle tissue development $(\mathrm{P}=0.00773)$ and positive regulation of nuclear factor-kB transcription factor activity $(\mathrm{P}=0.00485)$ (Table II). The
Table V. DEGs in the top $10 \%$ of nodes with a high connectivity degree in the PPI.

\begin{tabular}{|c|c|}
\hline DEG & STRING degree of connectivity \\
\hline$A K T 1$ & 37 \\
\hline EP300 & 25 \\
\hline CALM2 & 23 \\
\hline PIK3RI & 18 \\
\hline ATN1 & 11 \\
\hline PRKCZ & 11 \\
\hline SNRPDI & 10 \\
\hline$E E F 2$ & 10 \\
\hline MSH6 & 10 \\
\hline$E R B B 2$ & 9 \\
\hline$R B B P 7$ & 9 \\
\hline GNB2L1 & 9 \\
\hline TLR9 & 9 \\
\hline RRMI & 9 \\
\hline$B T K$ & 8 \\
\hline SLC $2 A 4$ & 8 \\
\hline TFIP11 & 8 \\
\hline$G R P$ & 8 \\
\hline DYNLT3 & 8 \\
\hline$A D R A 1 D$ & 7 \\
\hline$N A S P$ & 7 \\
\hline ARHGEF7 & 7 \\
\hline$T X N L 4 A$ & 7 \\
\hline$T X N$ & 7 \\
\hline$G R B 10$ & 7 \\
\hline
\end{tabular}

DEG, differentially-expressed gene; STRING, Search Tool for the Retrieval of Interacting Genes.

downregulated DEGs were identified to be enriched in 39 biological processes, including fat cell differentiation 


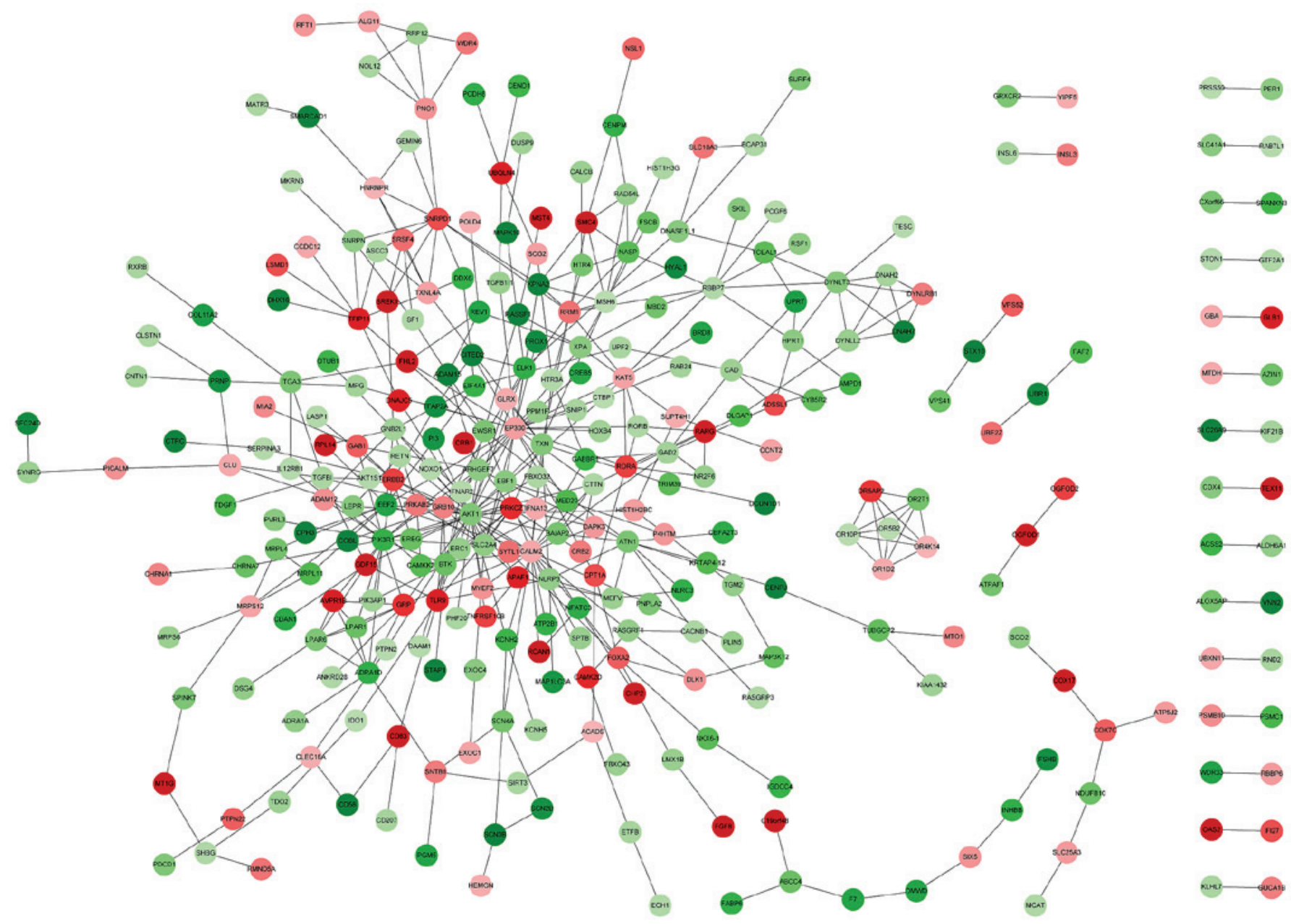

Figure 1. Search Tool for the Retrieval of Interacting Genes PPI network of the DEGs. Red and green nodes indicate upregulated and downregulated DEGs, respectively, in the habit group compared with the non-habit group. Darker shades represent higher llog2 fold-changel values. Lines indicate predicted or experimental PPIs. PPI network visualized using Cytoscape software. PPI, protein-protein interaction; DEG, differentially-expressed gene.

$(\mathrm{P}=0.00074)$, response to ultraviolet light $(\mathrm{P}=0.00118)$ and embryonic pattern specification $(\mathrm{P}=0.01686)$ (Table II).

KEGG enrichment analysis identified that the upregulated DEGs were significantly enriched in 9 signaling pathways, including that of calcium $(\mathrm{P}=0.01949)$, long-term potentiation $(\mathrm{P}=0.00326)$ and the spliceosome $(\mathrm{P}=0.02543)$ (Table III). The downregulated DEGs were significantly enriched in 5 signaling pathways, such as the adipocytokine signaling pathway $(\mathrm{P}=0.00374)$, the $\mathrm{B}$ cell receptor signaling pathway $(\mathrm{P}=0.00607)$ and the non-small cell lung cancer-associated signaling pathway $(\mathrm{P}=0.03098)$ (Table III).

Screening for TFs and TAGs. A total of 31 DEGs were identified as TFs, including 10 upregulated DEGs [e.g., E1A binding protein $\mathrm{p} 300$ (EP300), RARG and HOXB13] and 21 downregulated DEGs (e.g. CTBP1, GTF2Al and RORB) (Table IV). Furthermore, 41 DEGs were identified as TAGs, including 13 upregulated DEGs [e.g., erb-b2 receptor tyrosine kinase 2 (ERBB2), FGF8 and MLLT11] and 28 downregulated DEGs [e.g., AKT serine/threonine kinase 1 ( $A K T 1)$, $M L F 1$ and $F G F 20$ ] (Table IV).

Construction of the PPI network. The DEG PPI network was constructed using STRING. The resulting PPI network contained 330 nodes and 462 PPIs (Fig. 1). The top $10 \%$ of nodes were classified as having a high degree of connectivity in the PPI network, these included $A K T 1$, EP300, CALM2 and PIK3RI (Table V). AKTI was identified to interact with $E R B B 2$, epiregulin (EREG) and EP300 (Fig. 1).

Construction and analysis of the functional module. Based on the PPI network created, a functional module was constructed by BioNet. The functional module contained 33 nodes and 35 PPIs (Fig. 2). The connectivity degree of $A K T 1$, $C A L M 2, G N B 2 L 1$ and $E R B B 2$ was $>4$ in the functional module (data not shown). DEGs in the functional module were enriched in 18 biological processes defined by GO, including protein autophosphorylation $(\mathrm{P}=0.0000425)$, female pregnancy $(\mathrm{P}=0.00034)$, positive regulation of GTPase activity $(\mathrm{P}=0.00037)$ and cytokine-mediated signaling $(\mathrm{P}=0.00586)$ (Table VI). KEGG enrichment analysis demonstrated that the DEGs in the functional module were enriched in 16 signaling pathways, such as the ErbB signaling pathway ( $\mathrm{P}=0.00126$; e.g., EREG, ERBB2 and AKT1), the focal adhesion pathway $(\mathrm{P}=0.01310$; e.g., RASGRF1, ERBB2 and $A K T 1)$ and cancer-associated pathways $(\mathrm{P}=0.04696$; e.g., $D A P K 3, E R B B 2$ and ATK1) (Table VII). 


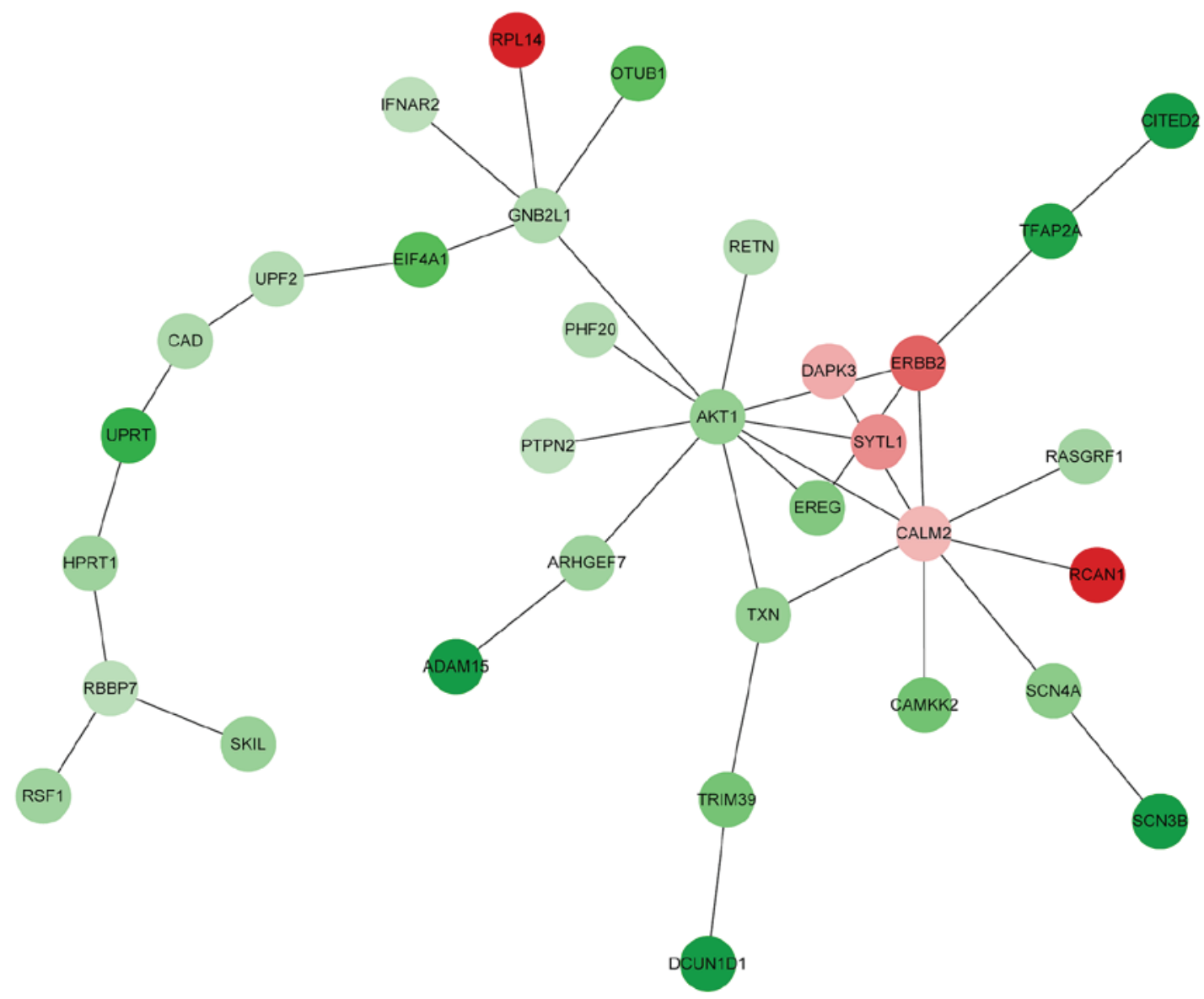

Figure 2. BioNet functional module within the Search Tool for the Retrieval of Interacting Genes protein-protein interaction network. Red and green nodes indicate upregulated and downregulated differentially-expressed genes, respectively, in the habit group compared with the non-habit group. Darker shades represent higher higher $\log 2$ fold-changel values. Lines indicate predicted or experimental interactions between proteins.

\section{Discussion}

Tongue cancer has been associated with a number of factors, including old age, geographical location and family history (7). In addition, tongue cancer is associated with certain habits, such as chewing betel nuts, smoking and alcohol abuse (3). Although knowledge of tongue cancer has progressed, the complex pathogenesis of the cancer remains unclear. Therefore, there is a requirement to investigate the molecular mechanisms underlying the pathogenesis of tongue cancer and to screen for novel markers of the disease. In the present study, the gene expression profiles of habit- and non-habit-associated tongue cancer samples were analyzed using bioinformatics methods. A total of 642 DEGs were identified between the habit and non-habit groups. Through analysis of the biological functions and pathways of the DEGs, a set of genes and signaling pathways was identified to be associated with habit-associated tongue cancer.

In the PPI network constructed, EP300 and AKT1 exhibited a high degree of connectivity. EP300, also known as p300, is a global transcriptional coactivator that regulates the activity of numerous DNA-binding transcription factors that are associated with a wide array of cellular activities, such as cell growth and differentiation $(20,21)$, which are increased in uncontrolled malignant tumors (22). EP300 has been found to be involved in DNA repair synthesis through its interaction with proliferating cell nuclear antigen, which is essential for DNA replication $(23,24)$. To the best of our knowledge, there is no evidence that EP300 is associated with habit-associated tongue cancer currently. However, EP300 has been found to promote cancer progression in the prostate (25) and colon (26). Thus, EP300 may serve a role in the development of habit-associated tongue cancer, likely through regulating cell growth.

AKT1 belongs to the Akt/protein kinase B subfamily of serine/threonine kinases, which is frequently hyperactivated in human cancer (27). The AKT family (AKT1-3) has been found to integrate extracellular signals in several cellular processes, including growth, proliferation, differentiation, migration and survival (28). Numerous studies have demonstrated that the phosphoinositide 3-kinase (PI3K)/AKT/mammalian target of rapamycin pathway serves an essential role in apoptosis and is frequently activated in numerous types of human cancer, such as head and neck squamous cell carcinoma $(29,30)$, prostate cancer $(31)$, breast cancer (32) and colorectal cancer (33). Cancer cells have a higher proliferation rate compared with wild-type cells and frequently lose the ability to undergo apoptosis (18). A previous study reported that activated AKT regulates its downstream targets to increase proliferation and decrease apoptosis in cells (34). AKT activation has been described as an early cellular response to carcinogen exposure and may 
Table VI. Top 10 enriched GO functions for DEGs in the functional module.

\begin{tabular}{|c|c|c|c|c|}
\hline GO no. & GO function & $\begin{array}{l}\text { No. of DEGs } \\
\text { enriched }\end{array}$ & P-value & Genes \\
\hline GO:0046777 & Protein autophosphorylation & 5 & 0.0000425 & $C A D, D A P K 3, C A M K K 2, E R B B 2, A K T 1$ \\
\hline GO:0007565 & Female pregnancy & 4 & 0.00034 & UPRT, CAD, CITED2, AKT1 \\
\hline GO:0043547 & Positive regulation of GTPase activity & 4 & 0.00037 & RASGRF1, ERBB2, ARHGEF7, GNB2L1 \\
\hline GO:0019221 & Cytokine-mediated signaling pathway & 4 & 0.00586 & IFNAR2, EIF4A1, EREG, PTPN2 \\
\hline GO:0042059 & $\begin{array}{l}\text { Negative regulation of epidermal } \\
\text { growth factor receptor signaling } \\
\text { pathway }\end{array}$ & 3 & 0.0000918 & TFAP2A, PTPN2, ARHGEF7 \\
\hline GO:0042593 & Glucose homeostasis & 3 & 0.00340 & $P T P N 2, T X N, A K T 1$ \\
\hline GO:0051151 & $\begin{array}{l}\text { Negative regulation of smooth muscle } \\
\text { cell differentiation }\end{array}$ & 2 & 0.00016 & RCAN1, EREG \\
\hline GO:0006222 & UMP biosynthetic process & 2 & 0.00025 & $U P R T, C A D$ \\
\hline GO:0010765 & $\begin{array}{l}\text { Positive regulation of sodium ion } \\
\text { transport }\end{array}$ & 2 & 0.00075 & $A K T 1, S C N 3 B$ \\
\hline GO:0021602 & Cranial nerve morphogenesis & 2 & 0.00092 & TFAP2A, CITED2 \\
\hline
\end{tabular}

${ }^{a}$ Fisher's exact test. GO, gene ontology; DEG, differentially-expressed gene; GTPase, guanosine triphosphatase; UMP, uracil monophosphate.

Table VII. Enriched KEGG signaling pathways for DEGs in the functional module.

\begin{tabular}{|c|c|c|c|c|}
\hline KEGG no. & KEGG signaling pathway & $\begin{array}{c}\text { No. of DEGs } \\
\text { enriched }\end{array}$ & P-value ${ }^{a}$ & Genes \\
\hline 4012 & ErbB signaling pathway & 3 & 0.00126 & $E R E G, E R B B 2, A K T 1$ \\
\hline 4510 & Focal adhesion & 3 & 0.01310 & RASGRF1, ERBB2, AKT1 \\
\hline 5200 & Pathways in cancer & 3 & 0.04696 & $D A P K 3, E R B B 2, A K T 1$ \\
\hline 5219 & Bladder cancer & 2 & 0.00495 & $D A P K 3, E R B B 2$ \\
\hline 5213 & Endometrial cancer & 2 & 0.00751 & $E R B B 2, A K T 1$ \\
\hline 5223 & Non-small cell lung cancer & 2 & 0.00808 & $E R B B 2, A K T 1$ \\
\hline 5214 & Glioma & 2 & 0.01155 & $A K T 1, C A L M 2$ \\
\hline 4920 & Adipocytokine signaling pathway & 2 & 0.01260 & $C A M K K 2, A K T 1$ \\
\hline 5212 & Pancreatic cancer & 2 & 0.01332 & $E R B B 2, A K T 1$ \\
\hline 5215 & Prostate cancer & 2 & 0.02100 & $E R B B 2, A K T 1$ \\
\hline
\end{tabular}

${ }^{\text {a} F i s h e r ' s ~ e x a c t ~ t e s t . ~ K E G G, ~ K y o t o ~ E n c y c l o p e d i a ~ o f ~ G e n e s ~ a n d ~ G e n o m e s ; ~ D E G, ~ d i f f e r e n t i a l l y-e x p r e s s e d ~ g e n e s . ~}$

be a key step in environmental carcinogenesis (35). In the current study, $A K T 1$ was identified to be significantly functionally enriched in cancer-associated signaling pathways. The overexpression of AKT has been detected in a variety of cancer types, including tongue cancer (36), head and neck squamous cell carcinoma (37), ovarian cancer (38) and prostate cancer (39). There is no evidence, to the best of our knowledge, that $A K T 1$ is associated with habit-associated tongue cancer at present. However, AKT1 may be associated with the development of habit-associated tongue cancer via the regulation of cell proliferation and differentiation.

In the current study, $A K T 1, E R B B 2$ and $E R E G$ were demonstrated to be significantly functionally enriched in the ErbB signaling pathway. The ErbB signaling pathway regulates cell migration and invasion in normal and tumor mammary epithelial cells (40). The ErbB family, which consists of four members [epidermal growth factor receptor (EGFR), ERBB2, ERBB3 and ERBB4], plays an important role in cell proliferation and survival in numerous epithelial malignancies (41). ERBB2 was predicted to be a TAG in the current study. The overexpression of ERBB2 particularly occurs with a high frequency in breast cancer (42). In addition, Silva et al (43) reported that ERBB2 expression is associated with the 10-year survival of patients with tongue cancer (43), indicating that ERBB2 serves an important role in tongue cancer development and progression. However, to the best of our knowledge, there have been no reports of an association between ERBB2 and habit-associated tongue cancer thus far. EGFR regulates cell motility, invasion and proliferation (44). EGFR mutations have been identified to activate anti-apoptotic signaling pathways, such as PI3K/AKT/mTOR and mitogen-activated protein kinase (45). EREG, as a 
ligand of EGFR, stimulates the EGFR signaling pathway, which promotes the metastasis of breast cancer cells (46). The results of the current study identified that AKT1 interacts with EREG in the PPI network. In addition, AKT1 and ERBB2 were classified as oncogenes using the TAG database. These results indicate that AKT1, ERBB2 and EREG are associated with the tumorigenesis of habit-associated tongue cancer and are potential therapeutic targets for the treatment of this cancer.

The grade of the tumor samples in the microarray dataset used in the present study was different between the habit and non-habit groups (Table I). The grade of the tumor may impact gene expression, so this should be taken into consideration when interpreting the results. In future, a more accurate comparison could be made if tumor samples of different grades were divided into subgroups. In addition, the results of the present study will be validated experimentally.

In conclusion, the present study identified key DEGs in habit-associated tongue cancer. These DEGs, such as $A K T 1$, $E P 300, E R B B 2$ and $E R E G$, may serve important roles in the tumorigenesis of habit-associated tongue cancer and could be used as therapeutic targets for the treatment of this cancer. However, further experiments are required to verify the results of the current study and increase our understanding of the pathogenesis of habit-associated tongue cancer.

\section{References}

1. Böckelman C,Hagström J, Mäkinen L, Keski-Säntti H, Häyry V, Lundin J, Atula T, Ristimäki A and Haglund C: High CIP2A immunoreactivity is an independent prognostic indicator in early-stage tongue cancer. Br J Cancer 104: 1890-1895, 2011.

2. Sano D and Myers JN: Metastasis of squamous cell carcinoma of the oral tongue. Cancer Metastasis Rev 26: 645-662, 2007.

3. Gosselin BJ: Malignant Tumors of the Mobile Tongue. Medscape, Jun 2011. http://emedicine.medscape.com/ article/847428-overview. Accessed April 3, 2015.

4. Liang XH, Lewis J, Foote R, Smith D and Kademani D Prevalence and significance of human papillomavirus in oral tongue cancer: The Mayo Clinic experience. J Oral Maxillofac Surg 66: 1875-1880, 2008

5. Liu Z, Wang $\mathrm{H}$ and Li Q: Tongue tumor detection in medical hyperspectral images. Sensors 12: 162-174, 2011.

6. Garavello W, Spreafico R and Gaini RM: Oral tongue cancer in young patients: A matched analysis. Oral Oncol 43: 894-897, 2007.

7. Moore SR, Johnson NW, Pierce AM and Wilson DF: The epidemiology of tongue cancer: a review of global incidence. Oral Dis 6: 75-84, 2000

8. Sebastian P, Babu JM, Prathibha R, Hariharan R and Pillai MR: Anterior tongue cancer with no history of tobacco and alcohol use may be a distinct molecular and clinical entity. J Oral Pathol Med 43: 593-599, 2014.

9. Xie X, Clausen OP, De Angelis P and Boysen M: The prognostic value of spontaneous apoptosis, Bax, Bcl-2, and p53 in ora squamous cell carcinoma of the tongue. Cancer 86: 913-920, 1999.

10. Seo J and Hoffman EP: Probe set algorithms: Is there a rational best bet? BMC Bioinformatics 7: 395, 2006.

11. Wettenhall JM and Smyth GK: limmaGUI: A graphical user interface for linear modeling of microarray data. Bioinformatics 20: 3705-3706, 2004.

12. Huang DW, Sherman BT, Tan Q, Collins JR, Alvord WG, Roayaei J, Stephens R, Baseler MW, Lane HC and Lempicki RA: The DAVID Gene Functional Classification Tool: A novel biological module-centric algorithm to functionally analyze large gene lists. Genome Biol 8: R183, 2007.

13. Gene Ontology Consortium: Gene ontology consortium: Going forward. Nucleic Acids Res 43: D1049-D1056, 2015.

14. Kanehisa M, Goto S, Furumichi M, Tanabe M and Hirakawa M: KEGG for representation and analysis of molecular networks involving diseases and drugs. Nucleic Acids Res 38: D355-D360, 2010.
15. ENCODE Project Consortium: An integrated encyclopedia of DNA elements in the human genome. Nature 489: 57-74, 2012.

16. Chen JS, Hung WS, Chan HH, Tsai SJ and Sun HS: In silico identification of oncogenic potential of fyn-related kinase in hepatocellular carcinoma. Bioinformatics 29: 420-427, 2013.

17. Von Mering C, Huynen M, Jaeggi D, Schmidt S, Bork P and Snel B: STRING: A database of predicted functional associations between proteins. Nucleic Acids Res 31: 258-261, 2003.

18. Kohl M, Wiese S and Warscheid B: Cytoscape: Software for visualization and analysis of biological networks. Methods Mol Biol 696 291-303, 2011.

19. Beisser D, Klau GW, Dandekar T, Müller T and Dittrich MT: BioNet: An R-Package for the functional analysis of biological networks. Bioinformatics 26: 1129-1130, 2010.

20. Ogryzko VV, Schiltz RL, Russanova V, Howard BH and Nakatani Y: The transcriptional coactivators p300 and CBP are histone acetyltransferases. Cell 87: 953-959, 1996.

21. Kalkhoven E: CBP and p300: HATs for different occasions. Biochem Pharmacol 68: 1145-1155, 2004.

22. Lahtz C and Pfeifer GP: Epigenetic changes of DNA repair genes in cancer. J Mol Cell Biol 3: 51-58, 2011.

23. Hasan S, Hassa PO, Imhof R and Hottiger MO: Transcription coactivator $\mathrm{p} 300$ binds PCNA and may have a role in DNA repair synthesis. Nature 410: 387-391, 2001

24. Moldovan GL, Pfander B and Jentsch S: PCNA, the maestro of the replication fork. Cell 129: 665-679, 2007.

25. Debes JD, Sebo TJ, Lohse CM, Murphy LM, Haugen DA and Tindall DJ: p300 in prostate cancer proliferation and progression. Cancer Res 63: 7638-7640, 2003

26. Ionov Y, Matsui S and Cowell JK: A role for p300/CREB binding protein genes in promoting cancer progression in colon cancer cell lines with microsatellite instability. Proc Natl Acad Sci USA 101: 1273-1278, 2004

27. Ju X, Katiyar S, Wang C, Liu M, Jiao X, Li S, Zhou J, Turner J, Lisanti MP, Russell RG, et al: Aktl governs breast cancer progression in vivo. Proc Natl Acad Sci USA 104: 7438-7443, 2007.

28. Freeman-Cook KD, Autry C, Borzillo G, Gordon D, Barbacci-Tobin E, Bernardo V, Briere D, Clark T, Corbett M, Jakubczak J, et al: Design of selective, ATP-competitive inhibitors of Akt. J Med Chem 53: 4615-4622, 2010

29. Pfisterer K, Fusi A, Klinghammer K, Knödler M, Nonnenmacher A and Keilholz U: PI3K/PTEN/AKT/mTOR polymorphisms: association with clinical outcome in patients with head and neck squamous cell carcinoma receiving cetuximab-docetax. Head Neck 37: 471-478, 2015.

30. Amornphimoltham P, Patel V, Molinolo A and Gutkind JS: Head and Neck Cancer and the PI3K/Akt/mTOR Signaling Network: Novel Molecular Targeted Therapies. Signaling Pathways in Squamous Cancer pp407-pp429, 2010.

31. Kong L, Schäfer G, Bu H, Zhang Y, Zhang Y and Klocker H: Lamin $\mathrm{A} / \mathrm{C}$ protein is overexpressed in tissue-invading prostate cancer and promotes prostate cancer cell growth, migration and invasion through the PI3K/AKT/PTEN pathway. Carcinogenesis 33: 751-759, 2012.

32. Castaneda CA, Cortes-Funes H, Gomez HL and Ciruelos EM: The phosphatidyl inositol 3-kinase/AKT signaling pathway in breast cancer. Cancer Metastasis Rev 29: 751-759, 2010.

33. Eide PW, Cekaite L, Danielsen SA, Eilertsen IA, Kjenseth A, Fykerud TA, Ågesen TH,Bruun J, Rivedal E, Lothe RA and Leithe E: NEDD4 is overexpressed in colorectal cancer and promotes colonic cell growth independently of the PI3K/PTEN/AKT pathway. Cell Signal 25: 12-18, 2013.

34. Weber SM, Bornstein S, Li Y, Malkoski SP, Wang D, Rustgi AK, Kulesz-Martin MF, Wang XJ and Lu SL: Tobacco-specific carcinogen nitrosamine 4-(methylnitrosamino)-1-(3-pyridyl)-1-b utanone induces AKT activation in head and neck epithelia. Int J Oncol 39: 1193-1198, 2011.

35. West KA, Brognard J, Clark AS, Linnoila IR, Yang X, Swain SM, Harris C, Belinsky S and Dennis PA: Rapid Akt activation by nicotine and a tobacco carcinogen modulates the phenotype of normal human airway epithelial cells. J Clin Invest 111: 81-90, 2003.

36. Massarelli E, Liu DD, Lee JJ, El-Naggar AK, Lo Muzio L, Staibano S, De Placido S, Myers JN and Papadimitrakopoulou VA: Akt activation correlates with adverse outcome in tongue cancer. Cancer 104: 2430-2436, 2005.

37. Amornphimoltham P, Sriuranpong V, Patel V, Benavides F, Conti CJ, Sauk J, Sausville EA, Molinolo AA and Gutkind JS: Persistent activation of the Akt pathway in head and neck squamous cell carcinoma: A potential target for UCN-01. Clin Cancer Res 10: 4029-4037, 2004. 
38. Altomare DA, Wang HQ, Skele KL, De Rienzo A, Klein-Szanto AJ, Godwin AK and Testa JR: AKT and mTOR phosphorylation is frequently detected in ovarian cancer and can be targeted to disrupt ovarian tumor cell growth. Oncogene 23: 5853-5857, 2004.

39. Lundstrom TS and Sobel JD: Antibiotics for gram-positive bacterial infections: Vancomycin, quinupristin-dalfopristin, linezolid, and daptomycin. Infect Dis Clin North Am 18: 651-668, x 2004.

40. Hardy KM, Booth BW, Hendrix MJ, Salomon DS and Strizzi L: ErbB/EGF signaling and EMT in mammary development and breast cancer. J Mammary Gland Biol Neoplasia 15: 191-199, 2010.

41. Yarden Y and Sliwkowski MX: Untangling the ErbB signalling network. Nat Rev Mol Cell Biol 2: 127-137, 2001.

42. Sosa MS, Lopez-Haber C, Yang C, Wang H, Lemmon MA, Busillo JM, Luo J, Benovic JL, Klein-Szanto A, Yagi H, et al: Identification of the Rac-GEF P-Rex1 as an essential mediator of ErbB signaling in breast cancer. Mol Cell 40: 877-892, 2010.
43. Silva SD, Perez DE, Alves FA, Nishimoto IN, Pinto CA, Kowalski LP and Graner E: ErbB2 and fatty acid synthase (FAS) expression in 102 squamous cell carcinomas of the tongue: Correlation with clinical outcomes. Oral Oncol 44: 484-490, 2008.

44. Lu Z, Jiang G, Blume-Jensen P and Hunter T: Epidermal growth factor-induced tumor cell invasion and metastasis initiated by dephosphorylation and downregulation of focal adhesion kinase. Mol Cell Biol 21: 4016-4031, 2001.

45. Uribe P and Gonzalez S: Epidermal growth factor receptor (EGFR) and squamous cell carcinoma of the skin: Molecular bases for EGFR-targeted therapy. Pathol Res Pract 207: 337-342, 2011

46. Nickerson NK, Gilmore JL, Allen KT, Riese DJ II, Nephew KP and Foley J: EGFR-Ligand signaling in breast cancer metastasis: Recurring developmental themes, 2011. 